\title{
ANALISA METALURGI BAJA PADUAN PADA SHACKLE KAPASITAS 12 TON SETELAH DILAKUKAN PROSES PEMANASAN DISERTAI PENDINGINAN
}

\author{
Idzani Muttaqin \\ Program Studi Teknik Industri, Fakultas Teknik \\ Universitas Islam Kalimantan Muhammad Arsyad Al Banjari \\ Jl. Adhyaksa No. 2 Kayu Tangi Banjarmasin 70123 \\ Email : idzanimuttaqin@gmail.com
}

\begin{abstract}
Abstrak- Dalam dunia Usaha kemajuan teknologi dan ilmu pengetahuan sekarang sangat cepat dan berkembang pesat. Akan tetapi terkadang dalam suatu proses produksi kita mengalami suatu gangguan produk dari sehingga produk yang dihasilkan akan menjadi tidak sesuai dengan keinginan. Untuk mengetahui kualitas bahan maka telah dilakukan penelitian terhadap pengaruh proses pemanasan disertai proses pendinginan terhadap kekerasan dan struktur mikro baja paduan, agar diketahui temperature dan media pendingin yang paling tepat untuk mendapatkan hasil kekerasaan yang baik.

Dalam penelitian ini baja paduan yang digunakan baja paduan Shackle kapasitas 12 ton. Untuk media pendinginan Udara, Air, Air Garam, Oli SAE $15 w-40$ dan temperature $600^{\circ} \mathrm{C}, 700^{\circ} \mathrm{C}$ dan $8^{\circ} \mathrm{C}$. Pengujian sifat mekanik yang dilakukan meliputi pengujian kekerasan dengan metode Brinell sedangkan pengujian metalografi dilakukan dengan menggunakan mikroskopoptik. Proses pemanasan disertai proses pendinginan memperlihatkan untuk media pendingin air temperature $800^{\circ} \mathrm{C}$ terjadi peningkatan kekerasan baja paduan Shackle kapasitas 12 ton makin besar. Hal ini terjadi karena rekristalisasi dan perubahan fasa pada logam. Hasil pengujian struktur mikro memperlihatkan bahwa material mempunyai struktur ferit, perlit, dan martensit. Dengan demikian dari penelitian ini didapat hasil untuk baja paduan shackle kapasitas 12 ton kombinasi yang terbaik adalah media pendingin air, temperatue $800^{\circ} \mathrm{C}$.
\end{abstract}

Kata Kunci : Baja Paduan, Kekerasan, Shackle dan Strukturmikro

\section{PENDAhUluaN}

$\mathrm{U}$ ntuk mengetahui kualitas suatu logam, pengujian sangat erat kaitannya dengan pemilihan bahan yang akan dipergunakan dalam konstruksi suatu alat, selain itu juga bias untuk membuktikan suatu teori yamg sudah ada atau pun penemuan baru dibidang metalurgi.

Dalam proses Produksi, dapat juga ditentukan jenis bahan maupun dimensinya, sehingga apabila tidak sesuai dapat dicari penggantinya yang lebih tepat disamping tidak mengabaikan faktor biaya produksi dan kualitasnya. Masalah yang dihadapi adalah sering rusaknya peralatan kerja Shackle kapasitas 12 ton berbahan baja paduan Sehingga untuk mengetahui seberapa besar perubahan permukaan dan pengerasan pada baja paduan Shackle kapasitas 12 ton perlu dilakukan pengujian dengan batasan tertentu, dalam penelitian yang akan dilakukan faktor yang akan diteliti pengaruhnya terhadap perubahan permukaan dan pengerasan pada baja paduan Shackle kapasitas 12 ton adalah pengaruh pendinginan.

Faktor perlakuan pendinginan adalah suatu perlakuan yang diterapkan pada logam agar diperoleh sifat fisis dan mekanis logam sesuai yang diinginkan. Adapun sifat mekanis dari logam antara lain: Kekerasan, keuletan dan kelelahan Sedangkan sifat fisisnya yaitu dimensi.

Baja

Baja adalah paduan besi dengan karbon sampai sekitar 1,7 $\%$. Baja Perkakas adalah adalah kelompok baja yang pada umumnya mempunyai kandungan Karbon dan juga paduan yang tinggi.

Baja adalah logam paduan dengan besi sebagai unsur dasar dan karbon sebagai unsur paduan utamanya. Kandungan karbon dalam baja berkisar antara $0.2 \%$ hingga $2.1 \%$. Fungsi karbon dalam baja adalah sebagai unsur pengeras dengan mencegah dislokasi bergeser pada kisi kristal (crystal lattice) atom besi.

Unsur paduan lain yang biasa ditambahkan selain karbon adalah mangan (manganese), krom (chromium), vanadium, dan tungsten. Dengan memvariasikan kandungan karbon dan unsur paduan lainnya, berbagai jenis kualitas baja bisa didapatkan. Penambahan kandungan karbon pada baja dapat meningkatkan kekerasan (hardness) dan kekuatan tariknya (tensile strength), namun di sisi lain membuatnya menjadi getas (brittle) serta menurunkan keuletannya (ductility).

Di samping unsur-unsur karbon sebagai campuran dasar dalam baja terdapat campuran-campuran paduan yang lain yang jumlah persentasinya disesuaikan dengan kebutuhan bahan yang akan dipergunakan. Unsur-unsur itu antara lain :

1. Mangan (Mn)

2. Silikon $(\mathrm{Si})$

3. Nikel (Ni)

4. $\operatorname{Kromium}(\mathrm{Cr})$

Sifat - sifat logam

Sifat-sifat dan karateristik suatu logam kaitannya erat dengan dalam penggunaan bahan ini di kehidupan sehari-hari, dan pemakainnya. Adapun kaitannya dengan sifat logam antara lain; Sifat Mekanis, Sifat Kemis, Sifat fisis, dan Sifat Teknologis

a. Sifat Mekanis

Sifat mekanis adalah kemampuan dan sifat suatu bahan untuk menahan beban yang dialami oleh bahan tersebut, baik beban statis, dinamis, atau berubah-ubah pada 
berbagai keadaan, pada suhu tinggi maupun nol derajat sekalipun

b. Sifat Fisis.

Sifat fisis suatu logam adalah bagaimana keadaan logam itu apabila mengalami peristiwa fisika, misalnya keadaan waktu terkena pengaruh panas dan pengaruh listrik. Karena pengaruh panas yang diterima pada suhu, bahkan akan mencair atau hanya, mengalami perubahan bentuk dan ukurannya

\section{c. Sifat Kemis}

Sifat kemis atau sifat kimia adalah bagaimana kondisi bahan tersebut mampu menahan adanya zat kimia yang dikenakan pada bahan tersebut. Misalnya, apakah bahan itu larut atau menjadi reaksi apabila terkena larutan asam, basa, dan garam. Apakah terjadi oksidasi jika terkena larutan atau bahan lain

d. Sifat Teknologis

Sifat Teknologis merupakan kemampuan suatu bahan dalam proses pengerjaanya secara teknis. Sifat-sifat itu meliputi: kemampuan bahan unutuk dilas, kemampuan untuk dikerjakan dengan mesin, kemampuan untuk bahan tuangan, dan kemampuan untuk penempaan. Sifat-sifat teknologis dari suatu bahan itu perlu diketahui sebelum pengolahan bahan dilakukan, misalnya, mampukah bahan itu dikerjakan dengan mesin perkakas, unutk mendapatkan hasil yang baik, dapatkah bahan itu dituang atau dicor tanpa penyusutan ukuran yang berarti, dan sebagainya.

\section{Struktur Baja}

Karbon dan besi terpadu secara kimiawi yang kemudian membentuk bahan lain, yaitu besi karbid (Fe3C) atau yang disebut dengan sementite. Baja termasuk dalam benda kristal karena memiliki struktur atom yang tersusun secara tertentu, yaitu atom - atom menempatkan diri secara beraturan (misalnya berbentuk kubus, tetragonal, rhombus dan hexagonal). Perubahan - perubahan yang di akibatkan perbedaan kadar karbon ditunjukan dari metallographi baja. Dengan naiknya kadar karbon $(\% \mathrm{C})$ maka noda flek hitam bertambah besar dan noda flek putih berkurang. Noda flek hitam itu adalah pearlite dan noda flek warna putih adalah ferrite (besi murni). Bentuk geometri dari persenyawaan logam besi dan baja berupa kubus, yang tersusun dari atom atomnya. Bentuk geometris inti adalah BCC ( Body Center Cubic), FCC (Face Center Cubic), HCP (Hexagonal Close Pocked).

a. Struktur Ferrite

Struktur ferrite sering juga disebut besi murni. Struktur ferrite dapat berubah - ubah sifat apabila dipanaskan.

b. Struktur Pearlite

Struktur pearlite adalah campuran ferrite dan cementite berlapis dalam suatu struktur butir. Laju pendinginan lambat menghasilkan pearlite kasar dan laju pendinginan cepat menghasilkan pearlite halus.

c. Struktur Sementite

Struktur sementite adalah suatu senyawa kimia antara besi (Fe) dan zat arang $\mathrm{C}$.

d. Struktur Austenite

Struktur austenite adalah struktur yang berasal dari struktur ferrite yang dipanaskan pada suhu $910{ }^{\circ} \mathrm{C}-1391{ }^{\circ} \mathrm{C}$ atau struktur pearlite yang dipanaskan pada suhu $723{ }^{\circ} \mathrm{C}-1392$ ${ }^{\circ} \mathrm{C}$

e. Sruktur Martensite

Struktur martensite merupakan fasa larutan padat lewat jenuh dari karbon dalam sel satuan tetragonal pusat badan atau Body Centered Tetragonal (BCT).

\section{METODE PENELITIAN}

Metode yang digunakan adalah metode eksperimen dengan proses perlakuan panas. Perlakuan panas adalah suatu metode yang digunakan untuk mengubah sifat fisik, dan kadangkadang sifat kimia dari suatu material, Secara umum perlakuan panas adalah memanaskan atau mendinginkan material, biasanya dalam suhu ekstrem, untuk mencapai hasil yang diinginkan seperti pengerasan atau pelunakan material, di mana pemanasan dan pendinginan dilakukan untuk tujuan mengubah sifat.

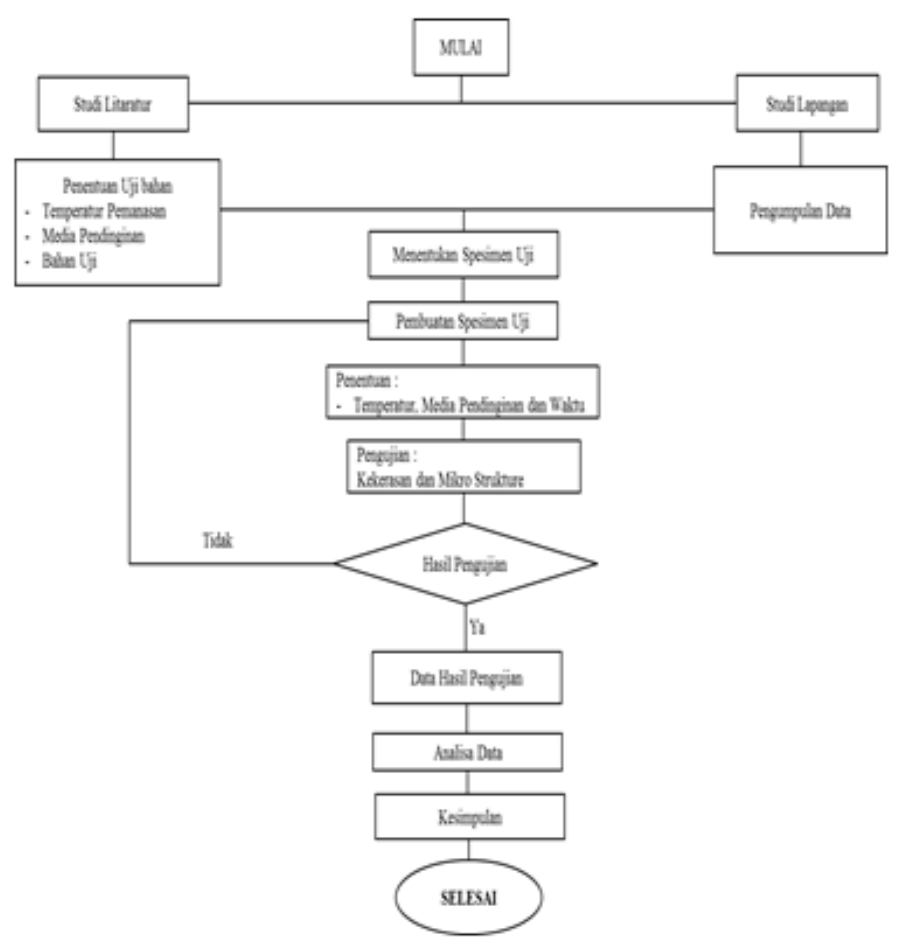

Gambar 1. Diagram Alir Penelitian

\section{HASIL DAN PEMBAHASAN}

Tabel 1. Uji Kekerasan Permukaan Baja paduan shackle kapasitas 12 Ton tanpa perlakuan panas dan media pendinginan (Media Dasar)

\begin{tabular}{|c|c|c|c|c|c|c|c|c|c|c|}
\hline \multirow{2}{*}{ No } & \multirow{2}{*}{ Sample } & \multicolumn{7}{|c|}{ Titik Uji } & $\begin{array}{c}\text { Rata - Rata } \\
\text { Brinell result } \\
\text { (HB) }\end{array}$ \\
\cline { 3 - 10 } & & 1 & 2 & 3 & 4 & 5 & 6 & 7 & 8 & $\mathbf{3 9 4 , 3 7 5}$ \\
\hline 1 & 1 & 469 & 400 & 442 & 335 & 362 & 387 & 348 & 412 & $\mathbf{3 9 4}$ \\
\hline
\end{tabular}


Tabel 2. Uji Kekerasan Permukaan Baja paduan shackle 12 ton dengan Temperature $600^{\circ} \mathrm{C}$

\begin{tabular}{|c|c|c|c|c|c|}
\hline \multirow{2}{*}{ No } & \multirow{2}{*}{$\begin{array}{l}\text { TITIK UJI } \\
\text { SAMPLE }\end{array}$} & \multicolumn{4}{|c|}{ MEDIA PENDINGINAN } \\
\hline & & UDARA & AIR & $\begin{array}{c}\text { AIR } \\
\text { GARAM }\end{array}$ & $\begin{array}{l}\text { OLI SAE } \\
15 W-40\end{array}$ \\
\hline 1 & 1 & 433 & 480 & 438 & 372 \\
\hline 2 & 2 & 419 & 505 & 451 & 342 \\
\hline 3 & 3 & 490 & 424 & 423 & 382 \\
\hline 4 & 4 & 399 & 385 & 359 & 425 \\
\hline 5 & 5 & 458 & 469 & 494 & 389 \\
\hline 6 & 6 & 437 & 411 & 451 & 457 \\
\hline 7 & 7 & 348 & 418 & 447 & 351 \\
\hline 8 & 8 & 446 & 456 & 411 & 431 \\
\hline & $\begin{array}{c}\text { Rata - Rata } \\
\text { Brinell result } \\
\text { (HB) }\end{array}$ & 428.75 & 443.500 & 434.25 & 393.625 \\
\hline
\end{tabular}

Tabel 3. Uji Kekerasan Permukaan Baja paduan shackle 12 ton dengan Temperature $700^{\circ} \mathrm{C}$

\begin{tabular}{|c|c|c|c|c|c|}
\hline \multirow{2}{*}{ No } & \multirow{2}{*}{$\begin{array}{l}\text { TITIK UJI } \\
\text { SAMPLE }\end{array}$} & \multicolumn{4}{|c|}{ MEDIA PENDINGINAN } \\
\hline & & UDARA & AIR & $\begin{array}{c}\text { AIR } \\
\text { GARAM }\end{array}$ & $\begin{array}{l}\text { OLI SAE } \\
15 W-40\end{array}$ \\
\hline 1 & 1 & 411 & 480 & 390 & 416 \\
\hline 2 & 2 & 413 & 453 & 483 & 396 \\
\hline 3 & 3 & 480 & 433 & 426 & 416 \\
\hline 4 & 4 & 489 & 464 & 394 & 358 \\
\hline 5 & 5 & 376 & 442 & 407 & 380 \\
\hline 6 & 6 & 387 & 432 & 399 & 338 \\
\hline 7 & 7 & 429 & 410 & 446 & 414 \\
\hline 8 & 8 & 375 & 456 & 424 & 390 \\
\hline & $\begin{array}{c}\text { Rata - Rata } \\
\text { Brinell result } \\
\text { (HB) }\end{array}$ & 420.00 & 446.25 & 421.125 & 338,50 \\
\hline
\end{tabular}

Tabel 4. Uji Kekerasan Permukaan Baja paduan shackle 12 ton dengan Temperature $800^{\circ} \mathrm{C}$

\begin{tabular}{|c|c|c|c|c|c|}
\hline \multirow{2}{*}{ NO } & \multirow{2}{*}{$\begin{array}{c}\text { TITIK UJI } \\
\text { SAMPLE }\end{array}$} & \multicolumn{4}{|c|}{ MEDIA PENDINGINAN } \\
\cline { 3 - 6 } & 1 & 398 & 532 & 441 & 391 \\
\hline 1 & 2 & 445 & 450 & 375 & 369 \\
\hline 2 & 3 & 403 & 475 & 414 & 317 \\
\hline 3 & 4 & 396 & 368 & 407 & 312 \\
\hline 4 & 5 & 375 & 414 & 442 & 345 \\
\hline 5 & 6 & 368 & 395 & 403 & 354 \\
\hline 6 & 7 & 418 & 556 & 441 & 373 \\
\hline 7 & 8 & 387 & 496 & 494 & 347 \\
\hline 8 & UIIR & OLI SAE \\
\hline \multicolumn{2}{|r|}{$\begin{array}{c}\text { Rata } \\
\text { Gata Brinell result } \\
\text { (HB) }\end{array}$} & $\mathbf{3 9 8 . 7 5}$ & $\mathbf{4 6 0 . 7 5}$ & $\mathbf{4 2 7 . 1 2 5}$ & $\mathbf{3 5 1 . 0 0}$ \\
\hline
\end{tabular}

Grafik Data Uji Rata-Rata Kekerasan Permukaan Baja paduan shackle kapasitas 12 ton selanjutnya dimasukan kedalam diagram seperti dibawah ini :

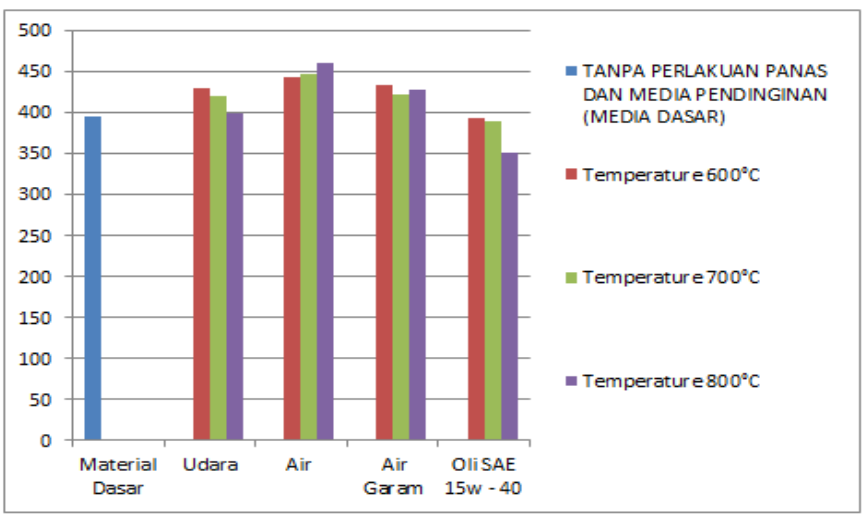

\section{KESIMPULAN}

Dari hasil penelitian yang telah dilakukan dapat ditarik kesimpulan seperti pada paparan berikut:

a. Angka uji kekerasan pada material netral sebelum dilakukan pengujian yaitu 394.375 HB, setelah dilakukan perlakuan panas dada temperature $800{ }^{\circ} \mathrm{C}$ pada material yang didinginkan dengan media pendingin air yaitu 460.75 HB atau terjadi peningkatan kekerasan sebesar $16.8 \%$ dari nilai material dasar.

b. Angka uji penurunan kekerasan terjadi material yang didinginkan dengan air murni yaitu $351.00 \mathrm{HB}$ dari nilai awal $394.375 \mathrm{HB}$ atau terjadi penurunan tingkat kekerasan dari nilai material dasar sebesar $11.00 \%$.

\section{DAFTAR PUSTAKA}

[1] Tata Surdia, Teknik Pengecoran Logam, Pradnya Paramita, Jakarta, 2000.

[2] Hay Green dan Bowyer, 1993, Kekuatan Mekanis. Surjono dan Wiganda, 1978, Teknologi Mekanik 2.

[3] T.R. Banga, Foundry Engineering, Khana Publishers, Nai Sarak, Delhi, 1981.

[4] Siswosuwarno, Teknik Pembentukan Logam, Jurusan Mesin ITB, 1986

[5] http:www.alatuji.com/article/detail/3/what-is-hardness-test-uji-kekerasan

[6] http://cyberships.wordpress.com/2012/06/02/proses-perlakuan-panas.

[7] http://news-and-education.blogspot.com/2013/10/perlakuan-panas-heattreatment.html

[8] http://sekolah007.blogspot.com/2013/04/karburasi-pada-logam-danpendinginan-html

[9] http://petersirami.blogspot.com/2011/02/baja.html

[10] http://blog.ub.ac.id/okkyardiansyah/2012/03/13/ttt-time-temperature-andtransformastion-diagram

[11] http://blog.ub.ac.id/okkyardiansyah/2012/03/13/ttt-time-temperature-andtransformation-diagram/

[12] http://www.infometrik.com/2011/08/perlakuan-panas-logam-1-diagram

[13] http://tabunginfo.blogspot.com/2011/06/heat-treatment-process.html

[14] http://agvnk.blogspot.com/2012/05/baja-dan-jenisnya.html

[15] http://mjpcenter.blogspot.com/2010/11/sifat-sifat-logam.html 